\title{
Author Correction: Ctenophore relationships and their placement as the sister group to all other animals
}

Nathan V. Whelan, Kevin M. Kocot, Tatiana P. Moroz, Krishanu Mukherjee, Peter Williams, Gustav Paulay, Leonid L. Moroz and Kenneth M. Halanych

Correction to: Nature Ecology \& Evolution http://doi.org/10.1038/s41559-017-0331-3 (2017); published online 9 October 2017.

In the version of this Article originally published the location of Punta Arenas was incorrect and should have read 'Chile' in Figures 3-5 and in the Supplementary Information. This has been corrected in all versions of the Article.

Published online online: 18 October 2017

https://doi.org/10.1038/s41559-017-0381-6 